\title{
Measuring the snowpack depth with Unmanned Aerial System photogrammetry: comparison with manual probing and a 3D laser scanning over a sample plot
}

Francesco Avanzi ${ }^{1, *}$, Alberto Bianchi ${ }^{1, *}$, Alberto Cina ${ }^{2, *}$, Carlo De Michele ${ }^{1, *}$, Paolo Maschio ${ }^{2, *}$, Diana Pagliari ${ }^{1, *}$, Daniele Passoni ${ }^{3, *}$, Livio Pinto ${ }^{1, *}$, Marco Piras $^{2, *}$, and Lorenzo Rossi ${ }^{1, *}$

${ }^{1}$ Politecnico di Milano, Department of Civil and Environmental Engineering, Piazza Leonardo da Vinci 32, 20133 Milano

${ }^{2}$ Politecnico di Torino, Department of Environment, Land and Infrastructure Engineering, Corso Duca degli Abruzzi 24, 10129 Torino

${ }^{3}$ Università degli Studi di Genova, Laboratory of Geodesy, Geomatics and GIS, Via Montallegro 1,16145 Genova

*Authors in alphabetic order

Correspondence to: Prof. Carlo De Michele, Politecnico di Milano, Department of Civil and Environmental Engineering, Piazza Leonardo da Vinci 32, 20133 Milano (carlo.demichele@ polimi.it)

\begin{abstract}
.
Photogrammetric surveys using Unmanned Aerial Systems (UAS) may represent an alternative to existing methods for measuring the distribution of snow, but additional efforts are still needed to establish this technique as a low-cost, yet precise tool. Importantly, existing works have mainly used sparse evaluation datasets that limit the insight into UAS performance

5 at high spatial resolutions. Here, we compare a UAS-based photogrammetric map of snow depth with data acquired with a MultiStation and with manual probing over a sample plot. The relatively high density of manual data (135 pt over $6700 \mathrm{~m}^{2}$, i.e., $2 \mathrm{pt} / 100 \mathrm{~m}^{2}$ ) enables to assess the performance of UAS in capturing the marked spatial variability of snow. The use of a MultiStation, which exploits a scanning principle, also enables to compare UAS data on snow with a frequently used instrument in high-resolution applications. Results show that the Root Mean Square Error (RMSE) between UAS and MultiStation data on snow is equal to $0.036 \mathrm{~m}$ when comparing the two point clouds. A large fraction of this difference may be, however, due to spurious differences between datasets due to simultaneous snowmelt, as the RMSE on bare soil is equal to $0.02 \mathrm{~m}$. When comparing UAS data with manual probing, the RMSE is equal to $0.31 \mathrm{~m}$, whereas the median difference is equal to 0.12 $\mathrm{m}$. The statistics significantly decrease up to RMSE $=0.17 \mathrm{~m}$ when excluding areas of likely water accumulation in snow and ice layers. These results suggest that UAS represent a competitive choice among existing techniques for high-precision, high-resolution remote sensing of snow.
\end{abstract}

\section{Introduction}

Monitoring snow distribution and amount is important for both water resource management and risk prevention (DeWalle and Rango, 2011). The amount of snow can be measured either as snow depth (HS, in m), or as snow water equivalent (SWE), i.e., the amount of water that would result from the complete melt of snow (in $\mathrm{mm}$ w.e. or $\mathrm{kg} / \mathrm{m}^{2}$, see Fierz et al. (2009)). 
The Cryosphere Discuss., doi:10.5194/tc-2017-57, 2017

Manuscript under review for journal The Cryosphere

Discussion started: 24 April 2017

(c) Author(s) 2017. CC-BY 3.0 License.

Both variables have been usually monitored by means of, e.g., snow pits or manual probing (Fierz et al., 2009), which are time consuming and may be risky in avalanche-prone, remote areas. HS can be also monitored using ultrasonic (Avanzi et al., 2014) or laser (Morin et al., 2012) depth sensors, while SWE can be monitored using e.g. snow pillows (Johnson and Marks, 2004) or cosmic rays (Morin et al., 2012). The significance of local measurements has been, however, debated (López Moreno et al., 2011; Grünewald and Lehning, 2015; López Moreno et al., 2015; Helbig and van Herwijnen, 2017), especially in view of the marked spatial variability of snow processes (Kattelmann, 1989; Schweizer et al., 2008; Grünewald et al., 2010; Scipión et al., 2013).

Recently, remote sensing has emerged as a non-invasive alternative for monitoring the snow water resource in quasi real-time. Importantly, remote sensing enables to observe the spatial patterns of snow and thus overcomes the possible undersampling of point measurements (Dietz et al., 2012; Sturm, 2015). Existing technological solutions include, among others, Terrestrial Laser Scanner (TLS) (e.g., see Jörg et al. (2006); Jaakkola et al. (2014); Prokop et al. (2008); Grünewald et al. (2010, 2013); Grünewald and Lehning (2015); Revuelto et al. (2016)), digital photogrammetry (Bühler et al., 2015; Nolan et al., 2015), tachymetry (Prokop et al., 2008), Ground Penetrating Radar (GPR) (Machguth et al., 2006), time-lapse photography (Farinotti et al., 2010; Parajka et al., 2012), or satellite-based sensors (Dietz et al., 2012). While the temporal-spatial resolution of satellite sensors is generally low for real-time forecasting at catchment-slope scale (Nolan et al., 2015) and optical data can be further affected by cloud coverage (Da Ronco and De Michele, 2014), laser scanning may need the instrument to be relocated for measuring HS in complex terrains (Bühler et al., 2016).

Some early attempts of using Unmanned Aerial Systems (UASs) on snow have been recently carried out. These systems are commonly used for high-resolution surveys (Thamm and Judex, 2006; Newcombe, 2007; Grenzdörffer et al., 2008; Gini et al., 2014; Niethammer et al., 2010; Molina et al., 2012; Nex and Remondino, 2014; Pagliari et al., 2016; Berni et al., 2009; Tauro et al., 2016). Moreover, it is quite simple to carry out the flight in an automatic way (Eisenbeiß, 2009; Colomina and Molina, 2014). The miniaturization of the imaging and of the positioning sensors reduces the payload and makes it possible to carry out flights up to about one hour long (Tao and Hansman, 2016). The increasing use of UAS is also related to the improvement of Structure from Motion (SfM), which allows to automatically obtain three-dimensional models from two-dimensional image sequences (Hartley and Zisserman, 2003; Koenderink and Van Doorn, 1991), and its combination with algorithms for automatic tie points extraction such as Scale Invariant Feature Transform (SIFT) (Lowe, 2004) and Speed-Up Robust Feature (SURF) (Bay et al., 2008). These state-of-the-art feature-based algorithms give several reliable matchings even in case of bad textured surfaces (El-Gayar et al., 2013; Lingua et al., 2009) .

Existing works about UAS on snow usually report an expected Root Mean Square Error (RMSE) for HS below $30 \mathrm{~cm}$ (e.g., see Vander Jagt et al. (2015); De Michele et al. (2016); Bühler et al. (2016); Harder et al. (2016); Lendzioch et al. (2016); Bühler et al. (2017)). Larger errors are usually attributed to vegetated areas (Bühler et al., 2016; Lendzioch et al., 2016). However, snow tends to form homogeneous surfaces and therefore it is often difficult to identify homologous points on different images of the photogrammetric block (Smith et al., 1967; Cline, 1993, 1994), especially in case of high resolution images where each frame covers only a small area. The use of modern SfM techniques, combined with the use of feature-extraction algorithms from Computer Vision, enables to recognize points even on very homogeneous surfaces (Adams, 2016; Vander Jagt et al., 
The Cryosphere Discuss., doi:10.5194/tc-2017-57, 2017

Manuscript under review for journal The Cryosphere

Discussion started: 24 April 2017

(c) Author(s) 2017. CC-BY 3.0 License.

2015). Existing works to evaluate the performances of UAS on snow have, however, mainly used sparse datasets at low density (Vander Jagt et al., 2015; De Michele et al., 2016; Bühler et al., 2016; Harder et al., 2016; Lendzioch et al., 2016), whereas only Bühler et al. (2017) present a one-day comparison with a TLS. Therefore, further efforts are highly needed to establish UAS as a low-cost, yet highly precise and promising tool for automatically monitoring snow at slope-catchment scale.

Here, we present a comparison between a UAS-based photogrammetric map of snow depth, co-located manual measurements (probing), and point clouds acquired with a Leica Nova MultiStation (MS) (Grimm, 2013). A MS acquires a point cloud by moving the telescope collimation axis and scanning the target scene at a very high frequency, i.e., up to 1000 points/s for distances smaller than $300 \mathrm{~m}$ (accuracy of $2 \mathrm{~mm}+2 \mathrm{ppm}$ ). The measurement principle is, therefore, different from that of a TLS, which uses a mirror to reflect the laser beam on the target scene. While a TLS enables to acquire a denser point cloud, its accuracy is in the order of centimeters, whereas a MS can reach the order of millimeters. Moreover, the Electronic Distance Meter of the MS has an operative wavelength equal to $658 \mathrm{~nm}$. For any snow grain size the reflectance of the laser beam is, therefore, between $90-100 \%$, whereas a TLS usually uses a wavelength between 800-1200 nm, which yields a reflectance below 70\% (Prokop et al., 2008). For both reasons, in this work the MS 3D point clouds will be used as a reference to evaluate the quality of the photogrammetric UAS survey.

15 The acquisition of point clouds on snow using a scanning principle represents a benchmark for high-resolution snow surveys and is a frequent choice in several applications (Jörg et al., 2006; Jaakkola et al., 2014; Bühler et al., 2015; Prokop et al., 2008; Grünewald et al., 2010, 2013; Grünewald and Lehning, 2015; Revuelto et al., 2016). To the best of authors' knowledge, this is however the first comparison between a UAS, a MS survey, and manual probing. The snow depth distribution is computed by comparing two different Digital Surface Models (DSM), i.e., a DSM of snow distribution (April 2016) and the DSM of bare soil (September 2016). The ground validation (in snow conditions) is carried out using 135 manual measurements of snow depth. The relatively high density of this dataset $\left(2 \mathrm{pt} / 100 \mathrm{~m}^{2}\right)$ enables to assess the key role that snow variability plays in ruling sensor performances; this is especially needed for UAS as it represents a recent technology for snow surveys.

The paper is organized as follows: Section 2 discusses the case study and introduces the instrumentation used. Section 3 presents and discusses the processing methodologies together with the results. Sections 4 and 5 report discussions and conclusions, respectively.

\section{The case study}

The study area is located close to the Belvedere glacier (Piedmont region, Italy, 45 57' 10.845”, $7^{\circ} 55^{\prime}, 5.2261$ ”, $2070 \mathrm{~m}$ a.s.1) and extends for about $6700 \mathrm{~m}^{2}$ (Fig. 1). The site is characterized by sparse rocks and grass, with no tree. The area is also crossed by two streams. While the topography is quite homogeneous (maximum variation of $\sim 7 \mathrm{~m}$ in correspondence of the highest rocks), the bare-ground coverage is variable and this enables to investigate the variability of sensor performances with different topographic features. During winter, this site is not easily accessible; this also guarantees that snow conditions are generally undisturbed. 
The Cryosphere Discuss., doi:10.5194/tc-2017-57, 2017

Manuscript under review for journal The Cryosphere

Discussion started: 24 April 2017

(c) Author(s) 2017. CC-BY 3.0 License.
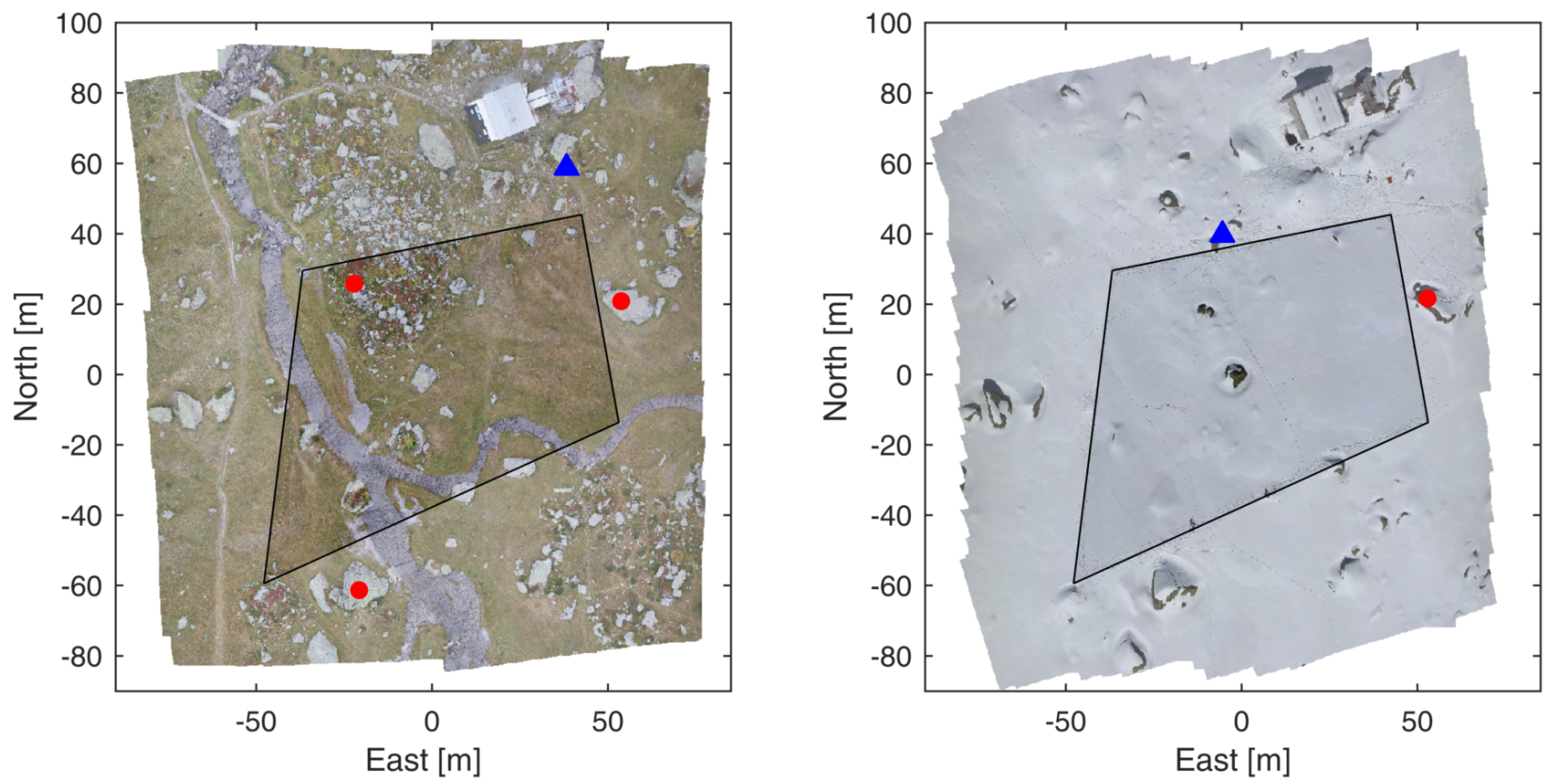

Figure 1. Morphology of the surveyed area during summer (left) and winter (right). The boundaries of the study area are in black. Red dots are the station points of the MultiStation, while the blue triangle represents the point used as angular reference.

Two different surveys are necessary to measure the depth and the distribution of the accumulated snow. A first survey during summer, when the snow is absent, is used to define the site topography and the reference, bare surface. A second survey is then carried out during peak accumulation. The differences between the multi-temporal estimated DSMs return a map of the snow depth distribution. The "summer" survey has been executed on 27th September 2016, while the acquisition at peak accumulation has been performed on 14th April 2016 (Fig. 1).

\subsection{UAS and MultiStation data acquisition}

UAS surveys were realized using a hexacopter produced by Microcopter. This system is equipped with an on-board low-cost GNSS receiver (Ublox LEA GH), a triaxial magnetometer and a MicroElectro-Mechanical System Inertial Measurement Unit (MEMS IMU). Its maximum payload is $0.500 \mathrm{~kg}$; the system is characterized by a flight autonomy of about 15 minutes. Images were acquired using a Canon EOS M camera with a fixed focal length of $22 \mathrm{~mm}$, equivalent to a focal length of $35 \mathrm{~mm}$ in full-frame format. Both flights were planned following the guidelines by Pagliari et al. (2016). The average flight height for the summer acquisition was about $65 \mathrm{~m}$, whereas it was about $60 \mathrm{~m}$ for the winter survey, which corresponds to an average 
The Cryosphere Discuss., doi:10.5194/tc-2017-57, 2017

Manuscript under review for journal The Cryosphere

Discussion started: 24 April 2017

(c) Author(s) 2017. CC-BY 3.0 License.

Ground Sample Distance (GSD) of about $0.02 \mathrm{~m}$. The summer images were acquired at about 10 AM (local time), while the winter survey was done around midday (local time).

The flights were arranged in 4 strips and the acquisition were planned to guarantee a high overlapping, i.e., about $80 \%$ for the along track direction and about $60 \%$ for the cross track one. The photogrammetric blocks were georeferenced using

5 Ground Control Points (GCPs), represented by black-and-white square targets. The bare-soil block (September 2016) was georeferenced using 16 GCPs, whereas only 8 GCPs were measured during the April survey to limit the perturbation of the snow surface. The position of both the summer and winter GCPs is given in the same reference frame, which is necessary to compute HS by means of a differentiation of photogrammetric DSMs. Therefore, two geodetic networks were realized and measured in the field, combining MS and GNSS measurements. GNSS measurements were only used to georeference the two surveys, while the MS (used in its Total Station mode) has been used to measure all the GCPs. To guarantee high redundancy, the survey was referred to some permanent GNSS stations (4 in the winter survey and 12 in the summer one), known in the ETRF2000(08) reference frame. The final adjustment leads to a centimetric accuracy for the position of GCPs for both cases in the global ETRF2000(08) reference frame.

The MS chosen was a Leica Nova MultiStation MS60. Since this device enables to acquire point clouds on a regular angular grid, these were acquired with a horizontal spacing between $0.01-0.10 \mathrm{~m}$, depending on the distance from the station point. During the summer survey, three station points were considered (Fig. 1): this results in $\sim 3 \times 10^{6}$ points, which cover the entire study area. On the contrary, only one station point (see again Fig.1) was used during the winter survey due to time restrictions. The resulting point cloud is composed by $\sim 1 \times 10^{6}$ points. While this results in a smaller scanned area during winter due to the topography of the study area (that presents increased obstructions and depressions in the middle), this choice is a trade-off between maximizing survey extension and minimizing snowmelt-due variations of the snow surface.

\subsection{Manual probing}

Point measurements of snow depth over the study area were performed using portable stakes (aluminum, diameter $\sim 1 \mathrm{~cm}$, resolution $1 \mathrm{~cm}$ ). To this end, a regular grid of points was defined and materialized in the field using ropes (see Section 3.3). The grid was composed by 12 courses; the average spacing between measurement points on the same course was $\sim 5 \mathrm{~m}$, which aimed at reasonably capturing the variability of the spatial patterns of snow depth at plot scale. Each measurement took a few minutes, whereas about two hours were needed to complete the manual survey (between 1 and 4 PM local time). This resulted in a slight decrease in the measured snow depth with time due to snowmelt (see Section 3). The position of each probing point has been measured using the MS, thus guaranteeing the co-registration with the GCPs used for the photogrammetric processing and with the MS point clouds. 
The Cryosphere Discuss., doi:10.5194/tc-2017-57, 2017

Manuscript under review for journal The Cryosphere

Discussion started: 24 April 2017

(c) Author(s) 2017. CC-BY 3.0 License.

Table 1. RMSE between the measured and estimated coordinates of Ground Control Points (GCPs).

\begin{tabular}{cccc}
\hline Flight season & $\mathrm{E}[\mathrm{m}]$ & $\mathrm{N}[\mathrm{m}]$ & $\mathrm{h}[\mathrm{m}]$ \\
\hline Summer & 0.010 & 0.007 & 0.005 \\
Winter & 0.017 & 0.010 & 0.004 \\
\hline
\end{tabular}

\section{Results}

\subsection{UAS photogrammetric blocks: processing}

Both the photogrammetric blocks were processed using Agisoft Photoscan (version 1.2.6) (www.agisoft.com). The summer block is composed by 84 images, while the winter one is composed by 144 images. Because searching correspondences (tie points) on snow may be difficult, a higher overlapping was used for the winter flight, which resulted in a larger number of frames. Each block was processed separately, following the standard photogrammetric procedure. First, tie points have been extracted from multiple images and the External Orientation (EO) parameters have been computed, constraining the block with the GCPs previously measured (bundle block adjustment). The accuracy of each GCP was specified for each coordinate, in agreement with the precision obtained from the geodetic network adjustment. Following this procedure, we ensured that the different observations were used together with their correspondent weight during the bundle block adjustment. During the bundle block adjustment, camera Internal Orientation (IO) parameters were also optimized by means of a self-calibration. This step is fundamental in case of a UAS survey, because of the disturbances to the system induced by take-off and landing, which can change these parameters compared to those obtained prior to the flight (Nex and Remondino, 2014). The empirical accuracies of GCPs for the two surveys are shown in Table 1.

For each survey, the photogrammetric dense point cloud was computed considering an image downscaling factor equal to 4, namely, two times for each image size. The generated point clouds are composed by about $50 \times 10^{6}$ points for the summer survey and $55 \times 10^{6}$ points for the winter set. Then, the DSM was derived considering a pixel size equal to $0.03 \mathrm{~m}$, as shown in Figure 2. This value was selected to have a cell size larger than the GSD, thus guaranteeing a sufficient number of observations for each cell.

\subsection{UAS vs. MultiStation}

The photogrammetric products for both surveys, i.e. dense point clouds and DSMs, were separately compared with the MS scans. The MS dataset was used to validate both the photogrammetric point cloud (C1), and the computed DSM (C2). A comparison using a MS-based DSM was avoided as its computation introduces additional interpolation errors. The MS scans were surveyed using the same geodetic network used for measuring the GCP, which guarantees the co-registration between the datasets. 
The Cryosphere Discuss., doi:10.5194/tc-2017-57, 2017

Manuscript under review for journal The Cryosphere

Discussion started: 24 April 2017

(c) Author(s) 2017. CC-BY 3.0 License.
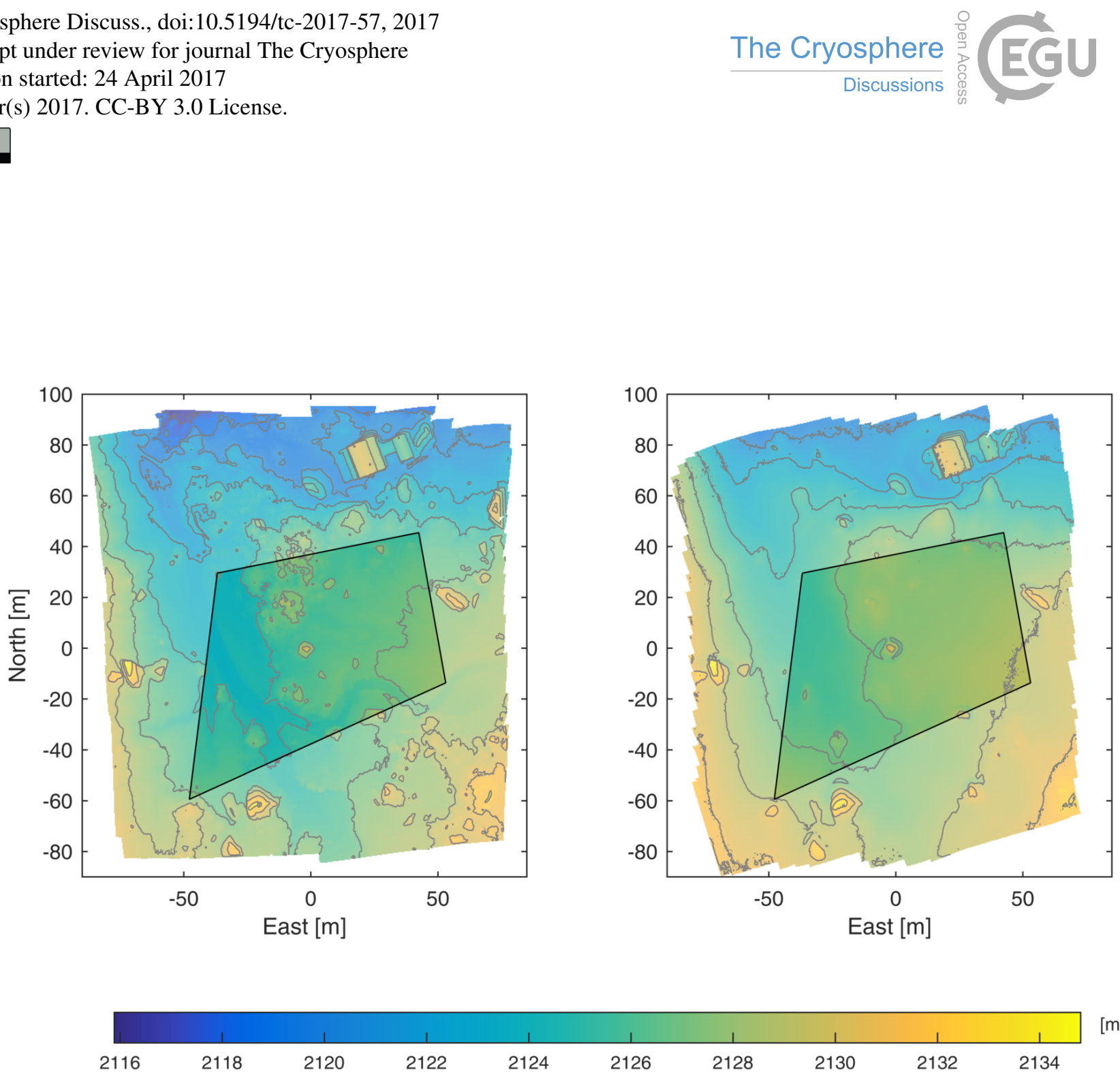

$[\mathrm{m}]$

Figure 2. The computed Digital Surface Models for the summer (left) and winter (right) UAS survey. The color legend represents surface height (ASL) and the contour lines (grey) are represented with an equidistant interval of $2 \mathrm{~m}$.

C1 was performed by computing the height difference between each point of the MS scan and its nearest neighbour in the photogrammetric point cloud, which was found basing on the shortest 3D distance. Because the photogrammetric point cloud presents some holes (due to shadows or poor matching over some areas of snowed surface), any resulting couple of points with a distance greater than $0.03 \mathrm{~m}$ in the horizontal plane was not included in the statistics. This corresponds to setting

5 a maximum horizontal search radius of $0.03 \mathrm{~m}$, which is assumed as the maximum acceptable distance between points on different datasets that make them physically correspondent. On the other hand, $\mathrm{C} 2$ was performed by interpolating the UAS 
The Cryosphere Discuss., doi:10.5194/tc-2017-57, 2017

Manuscript under review for journal The Cryosphere

Discussion started: 24 April 2017

(c) Author(s) 2017. CC-BY 3.0 License.

Table 2. Statistics of the winter and summer validation of the photogrammetric products using data from the MultiStation.

\begin{tabular}{ccccccc}
\hline & \multicolumn{3}{c}{ Point Cloud (C1) } & \multicolumn{3}{c}{ DSM (C2) } \\
Survey & Mean [m] & St. Dev. [m] & RMSE [m] & Mean [m] & St. Dev. [m] & RMSE [m] \\
\hline Summer & 0.004 & 0.020 & 0.020 & 0.001 & 0.068 & 0.068 \\
Winter & 0.026 & 0.025 & 0.036 & 0.041 & 0.056 & 0.069
\end{tabular}

DSM in correspondence of the horizontal coordinates of the MS point clouds and then comparing this interpolated height with that measured by the MS.

Table 2 reports (for each comparison) the mean and the standard deviation of the residuals between the UAS and the MS along with the corresponding RMSE. In all the cases, standard deviations are smaller than $6.8 \mathrm{~cm}$, which means that the and those of the UAS reads 0.97 in winter and 0.99 in summer. These results show that UAS can provide a map of snow depth distribution with a competitive accuracy to that of a MS.

\subsection{UAS vs. manual probing}

Figure 5(a) reports the scatter plot between UAS-based (henceforth, $\mathrm{HS}_{U A S}$ ) and manual (henceforth, $\mathrm{HS}_{M}$ ) measurements of two datasets are correlated (73\%), the difference between the data increases with a decreasing $\mathrm{HS}_{M}$. This plot also shows that 
The Cryosphere Discuss., doi:10.5194/tc-2017-57, 2017

Manuscript under review for journal The Cryosphere

Discussion started: 24 April 2017

(c) Author(s) 2017. CC-BY 3.0 License.
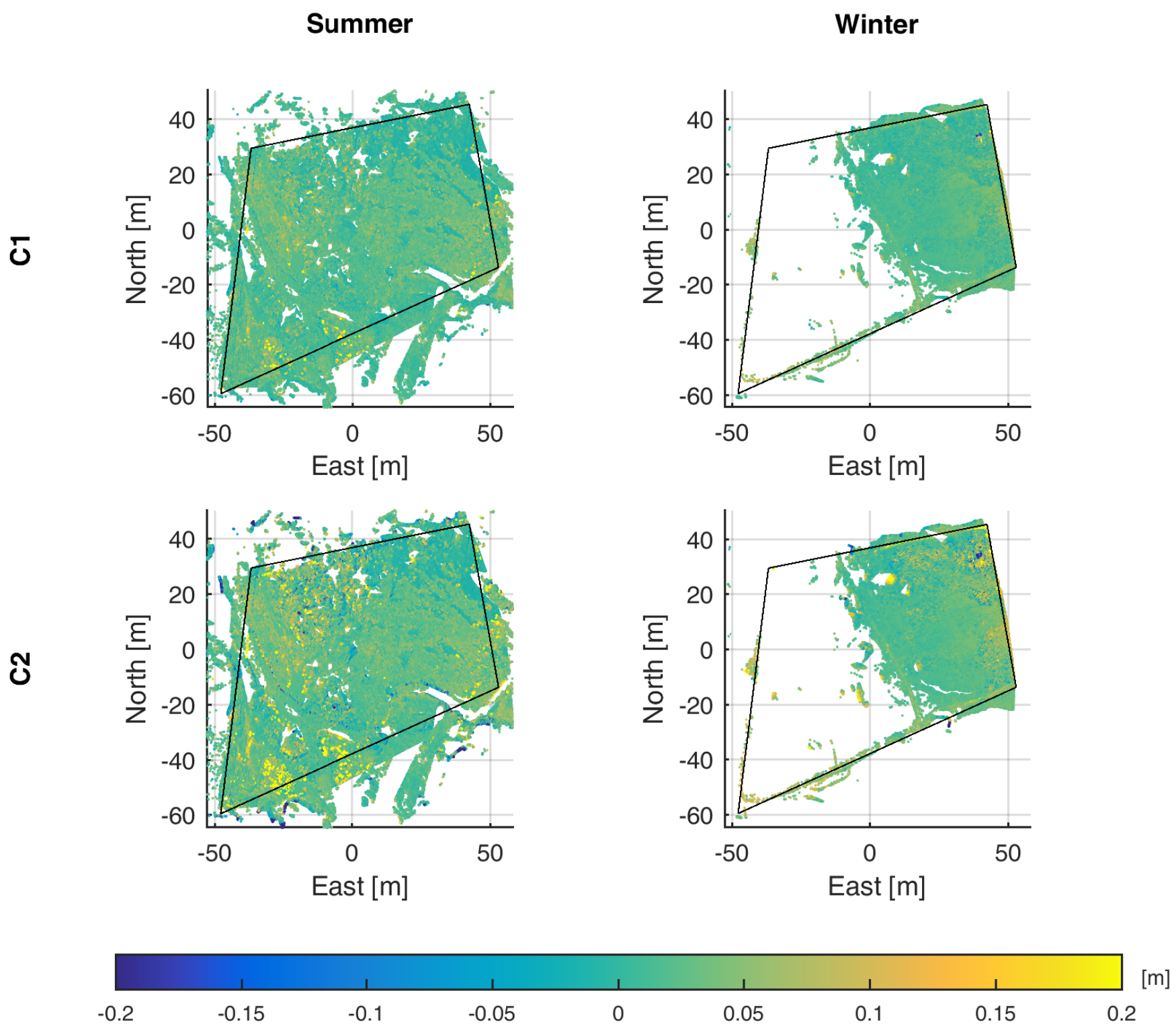

Figure 3. Height differences between the MultiStation (MS) dataset and the photogrammetric products (both summer and winter). C1 refers to the comparison between the MultiStation scan and the photogrammetric point cloud, whereas $\mathrm{C} 2$ refers to the comparison between the MultiStation scan and the computed DSM from UAS data.

the UAS-based HS is generally greater than the manual one, i.e., $\mathrm{HS}_{U A S}-\mathrm{HS}_{M}>0$ in $\sim 89 \%$ of the data. This reveals either a tendency to underestimate HS by manual probing or a tendency to overestimate it by photogrammetry and MS. 
The Cryosphere Discuss., doi:10.5194/tc-2017-57, 2017

Manuscript under review for journal The Cryosphere

Discussion started: 24 April 2017

(c) Author(s) 2017. CC-BY 3.0 License.

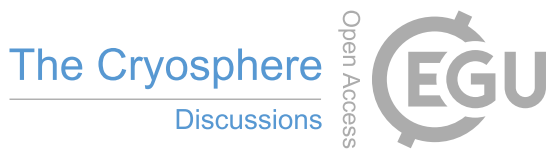

(c) $\underset{\mathrm{BY}}{(i)}$
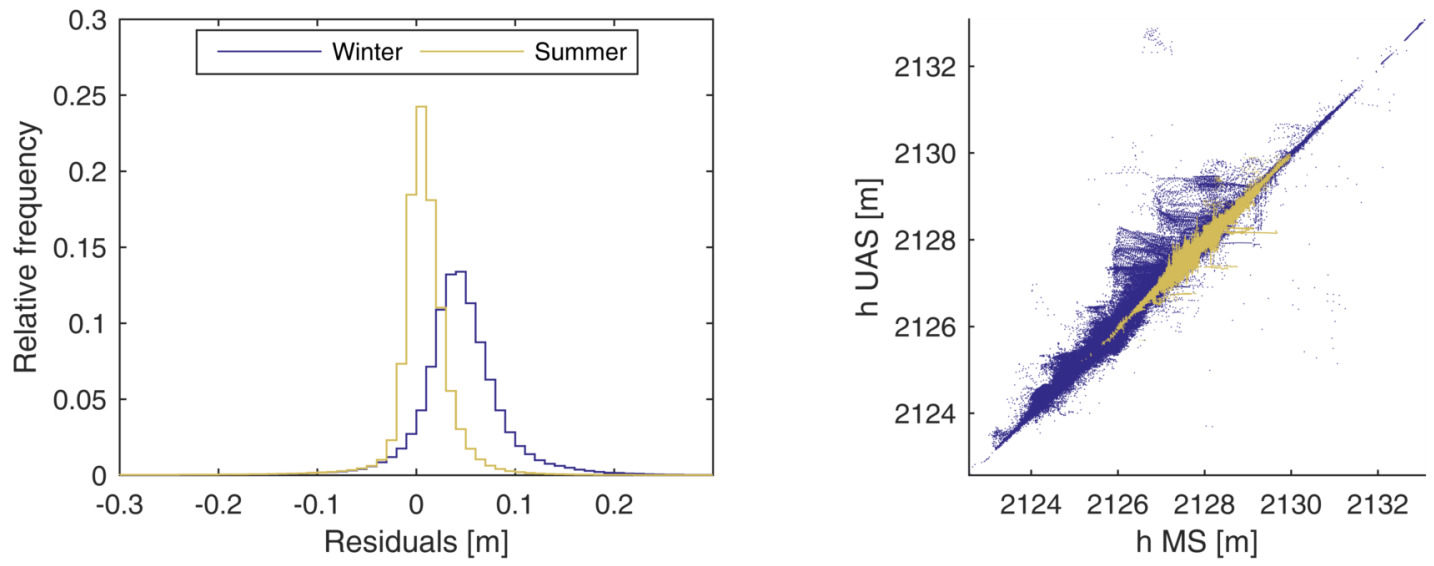

Figure 4. Histograms of the residuals between the MultiStation scan and the computed DSM from UAS data (C2), both winter and summer cases (left). Scatter plot of UAS-based vs. MS-based heights (ASL), both winter and summer cases (right).

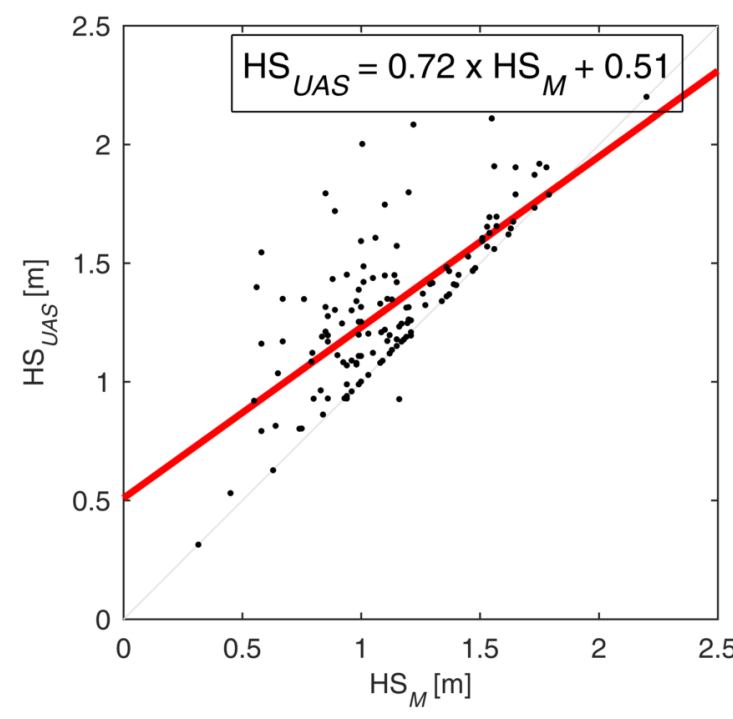

(a)

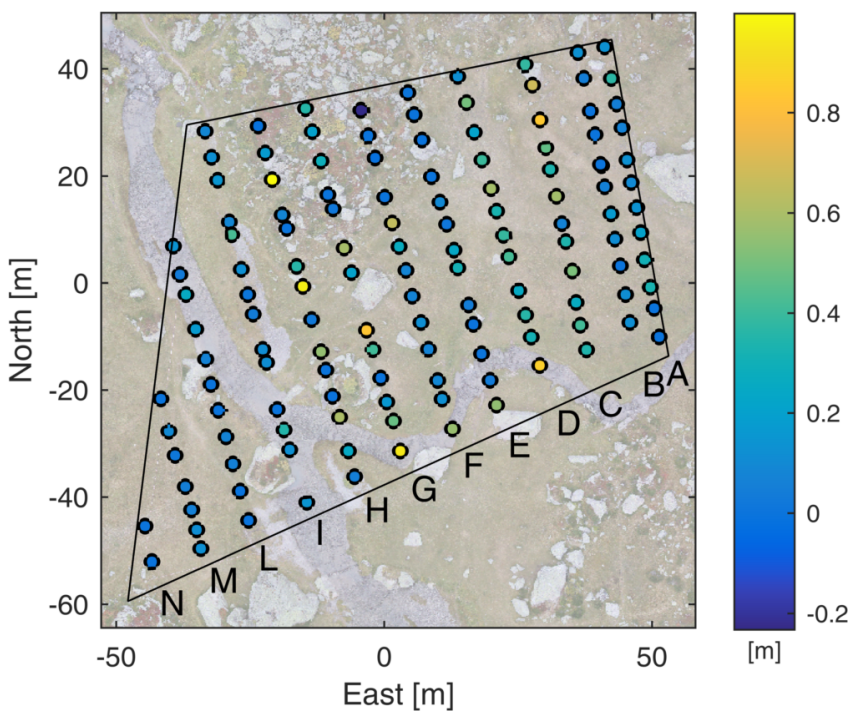

(b)

Figure 5. Evaluation of UAS data using manual probing. Fig.5(a): Scatter plot between UAS-based and manual measurements of HS (regression line in red). Fig.5(b): Spatial distribution of the differences between UAS-based and manual measurements of snow depth. The color legend represents the differences between UAS and manual probing.

The mean difference between the UAS-based DSM and the 135 manual measurements (henceforth, $\mathrm{HS}_{U A S}-\mathrm{HS}_{M}$ ) reads $0.20 \mathrm{~m}$, whereas the standard deviation is equal to $0.24 \mathrm{~m}$. This translates into a RMSE equal to $0.31 \mathrm{~m}$. The median difference is, however, equal to $0.12 \mathrm{~m}$. Because only $\sim 11 \%$ of the differences are negative, about $39 \%$ of the measurements are rather 
The Cryosphere Discuss., doi:10.5194/tc-2017-57, 2017

Manuscript under review for journal The Cryosphere

Discussion started: 24 April 2017

(c) Author(s) 2017. CC-BY 3.0 License.

Table 3. Statistics of the evaluation of UAS data using manual probing: Group 1 (courses A, B, E, F, I, L, M and N) vs. Group 2 (courses C, $\mathrm{D}, \mathrm{G}$, and $\mathrm{H})$.

\begin{tabular}{cccc}
\hline Group & Mean [m] & St. Dev. [m] & RMSE [m] \\
\hline Group 1 & 0.11 & 0.14 & 0.17 \\
Group 2 & 0.36 & 0.27 & 0.45 \\
\hline
\end{tabular}

small, i.e., between zero and the median. The first quartile is equal to $0.02 \mathrm{~m}$, whereas the third quartile is equal to $0.33 \mathrm{~m}$. The maximum difference is rather large $(\sim 1 \mathrm{~m})$, whereas the minimum difference is equal to $-0.23 \mathrm{~m}$.

Figure 5(b) shows the spatial distribution of the differences between the UAS-based DSM and the manual measurements. Along courses A, B, E, F, I, L, M and N (Group 1), this difference is generally small (see Table 3). Along courses C, D, G, and $\mathrm{H}$ (Group 2), the differences are spatially more variable (see again Table 3). Because the protocol as well as the manual probe was the same for all the courses, this discrepancy cannot be explained by a measurement error. While the differences are clustered along these courses, no evident spatial pattern in vegetation or soil coverage emerges that could clearly explain this mismatch.

\section{Discussion}

These results confirm the expected precision of a UAS photogrammetric flight in measuring the spatial variability of $\mathrm{HS}$ at $\mathrm{cm}$ scale. The obtained RMSE agrees with what reported before by e.g. De Michele et al. (2016) (0.14 m), Bühler et al. (2016) (less than 0.15 on rocks and less than $0.3 \mathrm{~m}$ on grass), Lendzioch et al. (2016) ( $0.22 \mathrm{~m}$ in open areas and $0.42 \mathrm{~m}$ in forests), or Harder et al. (2016) (between $0.085 \mathrm{~m}$ and $0.137 \mathrm{~m}$ ). Compared with most previous surveys, we focused here on a relatively dense grid. For example, Vander Jagt et al. (2015) used 37 measurements over $6900 \mathrm{~m}^{2}\left(0.5 \mathrm{pt} / 100 \mathrm{~m}^{2}\right)$, Bühler et al. (2015) took between $0.04 \mathrm{pt} / 100 \mathrm{~m}^{2}$ and $0.11 \mathrm{pt} / 100 \mathrm{~m}^{2}$, and Lendzioch et al. (2016) took between $0.04 \mathrm{pt} / 100 \mathrm{~m}^{2}$ and $0.2 \mathrm{pt} /$ $100 \mathrm{~m}^{2}$. Harder et al. (2016) considered wide areas $\left(0.65 \mathrm{~km}^{2}\right.$ and $\left.0.32 \mathrm{~km}^{2}\right)$, but one of the two study sites included intensive plots, which is comparable to our survey. Because the spatial variability of snow may be very large, even over short distances (López Moreno et al., 2015), the outcome of a comparison between UAS and manual proving may change with the spatial resolution of manual data. However, this survey revealed that increasing the number of points does not significantly affect the overall precision of the survey (i.e., the RMSE). UAS does represent a competitive choice among existing techniques for high-precision remote sensing of snow at high resolution.

Some spatial patterns emerge between measurement locations and measurement differences (see again Fig. 5), which results in an increase in RMSE for some specific courses compared to, e.g., De Michele et al. (2016); Bühler et al. (2016); Harder et al. (2016). In Figure 6, the position of the measurement points and the map of flow accumulation area have been shown over the DSM of the bare soil ( $0.03 \mathrm{~m}$ resolution). This map enables to estimate the drainage network of the study area, i.e., the 
The Cryosphere Discuss., doi:10.5194/tc-2017-57, 2017

Manuscript under review for journal The Cryosphere

Discussion started: 24 April 2017

(c) Author(s) 2017. CC-BY 3.0 License.

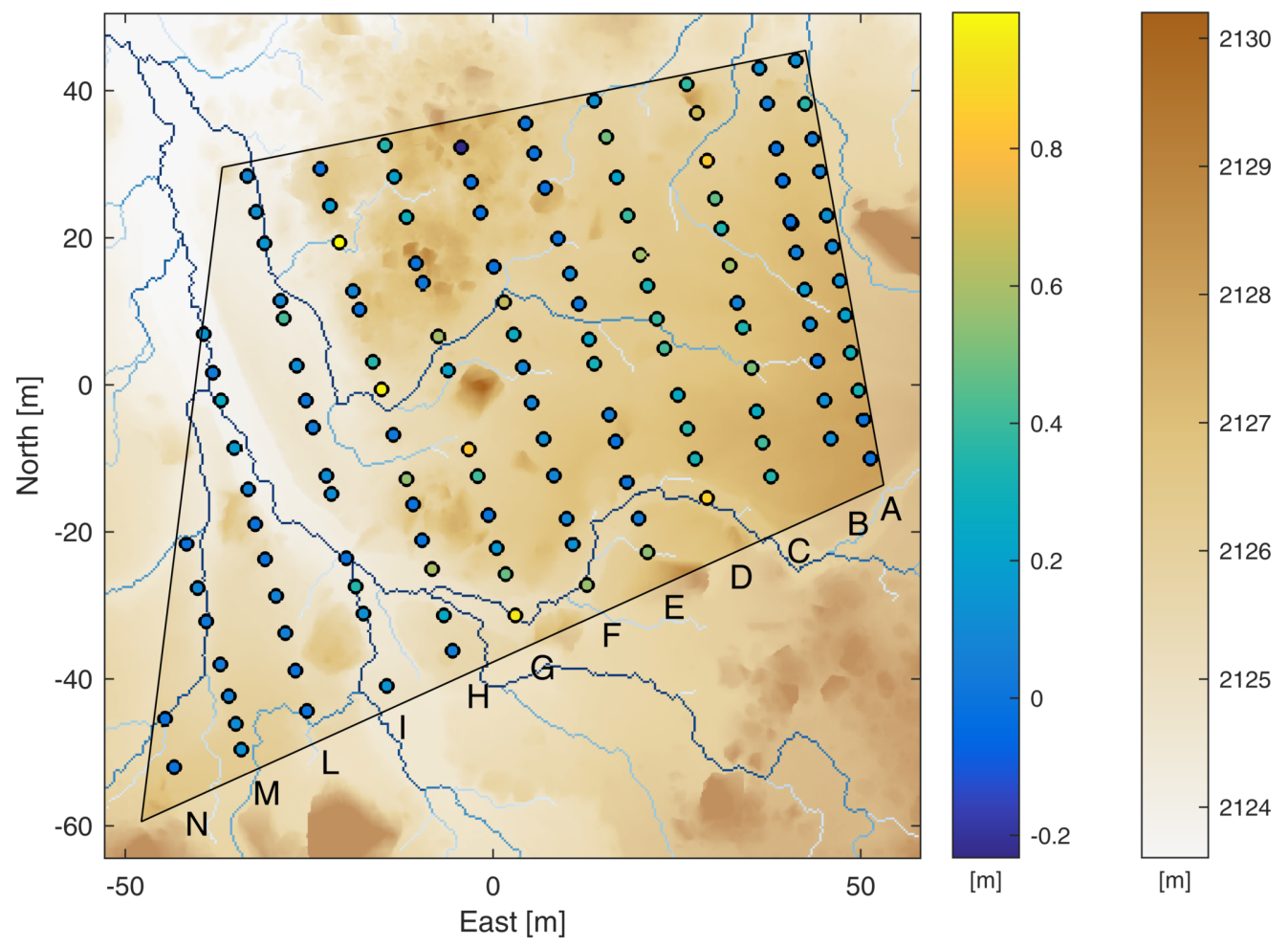

Figure 6. Drainage network over the study area: blue lines represent the areas of preferential flow drainage. The two color legends represent the differences between UAS and manual probing (left) and surface altitude (right), respectively.

areas of water concentration due to surface runoff. This shows that several larger differences are located in areas of marked flow accumulation, i.e., over the stream and/or over areas of preferential percolation of water over the plot.

The drainage network in melting snow is generally poorly constrained and may depend on several random effects, e.g., layering or preferential flow (Katsushima et al., 2013; Avanzi et al., 2016). Because gravity becomes the dominant driver

5 of liquid water flow in snow once the snowpack is ripe and isothermal (DeWalle and Rango, 2011), slope and elevation differences on the ground may be assumed as approximate, proxy variables for explaining the dominant directions of water movement in snow (Kattelmann and Dozier, 1999). The concentration of large differences between $\mathrm{HS}_{U A S}$ and $\mathrm{HS}_{M}$ in areas of flow accumulation might be, therefore, explained by the possible local concentration of water due to snowmelt and rainfall and its subsequent refreeze. The local development of ice layers could have prevented the probe from reaching the base of the snowpack, hence the large differences. This is also consistent with Fig. 5, which shows that manual probing tended to underestimate snow depth. The 2015 - 2016 snow season at the study site was marked by an early snowpack (October 2015) that persisted at the site up to January 2016 and created a shallow, dense base layer (up to $\sim 10-15 \mathrm{~cm}$ thick). Between January 
The Cryosphere Discuss., doi:10.5194/tc-2017-57, 2017

Manuscript under review for journal The Cryosphere

Discussion started: 24 April 2017

(c) Author(s) 2017. CC-BY 3.0 License.

and April 2016, the snowpack increased up to $\sim 150 \mathrm{~cm}$, but both melt-freeze episodes and rain-on-snow events occurred over the study area, especially in early April. Both processes, together with water retention at layer transitions due to capillary barriers (Avanzi et al., 2016), favor the development of ice layers. While no pit was excavated due to time constraints, ice layers were observed close to the two streams that cross the study area, where the snow cover was patchy.

The observed discrepancy between $\mathrm{HS}_{U A S}$ and $\mathrm{HS}_{M}$ leads to three important conclusions about UAS and manual surveys of snow depth. First, because larger differences may be the effect of local disturbances like ice layers, the statistics calculated on courses from Group 1 may be a more significant indication of sensor performance at this scale (i.e., RMSE $=0.17 \mathrm{~m}$ ). Second, because these discrepancies may be explained by microscale topography and importantly internal snow processes, a non-invasive technique like UAS may represent a more reliable solution than manual probing, which is also more timeconsuming and cannot retrieve the distribution of snow depth at this scale without significantly perturbing the snow cover. All these benefits support further efforts to replace existing manual courses (such as those carried out for hydrologic monitoring in mountain catchments) with remote sensing. Third, liquid water redistribution in snow and the associated stratigraphic features (like ice layers) may represent an important, but sometimes neglected, source of error for probing. The use of flow accumulation maps may provide a useful tool for predicting the areas where such errors may be expected. Some measurements on flowconcentration areas show a smaller difference between $\mathrm{HS}_{U A S}$ and $\mathrm{HS}_{M}$ (see for example courses M or N, Fig.s 5 and 6). This may be expected, as flow drainage networks in snow are spatially very variable due to inherently random effects like instability of the wetting front at microstructural transitions (Katsushima et al., 2013; Hirashima et al., 2014; Avanzi et al., 2016).

While several works have evaluated the accuracy of UAS flights on snow using manual probing, systematic comparisons with other high-resolution techniques are still lacking. This would represent an essential step in the evaluation of UAS because, as mentioned, their spatial resolution is much larger than that achievable using manual measurements. For example, the GSD of the UAS flights was about $0.02 \mathrm{~m}$ in this study, which is comparable to the diameter of a portable stake. It follows that further insight into the performance of UAS at high resolutions can only be achieved using other remote sensing devices, such as those using a scanning principle (Bühler et al., 2017). Our comparison with data from a MS reveals that the two point clouds are highly consistent (see Table 2). Such a high agreement suggests that the two techniques may provide comparable results. Moreover, the standard deviations of the residuals between the UAS and the MS point clouds are comparable for both the summer and winter cases (respectively 0.02 and $0.025 \mathrm{~m}$ ), which means that the noise introduced by a more difficult search and matching of tie-points over homogenous surfaces, such as snow, is minimal. A MS or TLS acquisition needs several stationing points to map snow depth over an irregular terrain, hence a longer survey, whereas UAS flights may suffer from strong wind, which is a frequent, yet variable condition in mountain areas. Therefore, this result suggests that the combination between scanning and photogrammetric techniques may enable to map snow depth with a high level of flexibility, e.g., under several weather or topographic conditions. The obtained RMSE is smaller than those reported by Bühler et al. (2017), who compared four UAS flights at different wavelengths and shadow conditions with a TLS (RMSE between $0.18 \mathrm{~m}$ and $0.77 \mathrm{~m}$ ). This reveals the expected increased accuracy of a MS compared to a TLS and further supports the high agreement between scanning and photogrammetric techniques on snow. Moreover, it is worth to note that the error distribution over the reconstructed surface is homogenous, in case of a flight planned and realized considering appropriate overlapping and a constant flight height (as for 
The Cryosphere Discuss., doi:10.5194/tc-2017-57, 2017

Manuscript under review for journal The Cryosphere

Discussion started: 24 April 2017

(c) Author(s) 2017. CC-BY 3.0 License.

the case here presented). On the contrary, the MS or TLS measurement precision depends on the distance between the station point and the investigated object (i.e., the distance travelled by the laser beam) and on the incidence angle.

\section{Conclusions}

Here, we have compared three different instruments used to collect snow depth, i.e., UAS, a MultiStation (MS), and manual

5 probing, over a sample plot $\left(6700 \mathrm{~m}^{2}\right)$. The snow depth distribution has been obtained for both UAS photogrammetry and MS by differentiation of the dataset in snow condition (April 2016) with the one on bare soil (September 2016).

Results show that the mean of the computed residuals between the MS and UAS point clouds is not significantly different from zero for the summer survey. For the winter case, a bias equal to $0.026 \mathrm{~m}$ has been found, which is mainly due to ongoing snowmelt between the UAS and the MS acquisitions (time difference of three hours). These results reflect the high consistency between the two datasets on both bare soil and snow. The standard deviations of the residuals are below $0.025 \mathrm{~m}$ for both the summer and the winter case. The small increase of the standard deviation on snow compared to that on bare soil (from 0.020 to $0.025 \mathrm{~m}$ ) is related to the more difficult automatic tie-points search on the relatively homogeneous surface of snow, which results in a noisier matching. When comparing the photogrammetric DSMs with the MS point clouds, an increase of the mean and the standard deviations of the residuals has been found. This is because a DSM interpolates a point cloud and introduces a smoothing effect, especially in correspondence of abrupt terrain variations.

The comparison between the UAS map and manual samplings has been carried out using a relatively dense, regular grid of 135 manual measurements $\left(\sim 2 \mathrm{pt} / 100 \mathrm{~m}^{2}\right)$. The obtained RMSE $(0.31 \mathrm{~m})$ agrees with previous works. However, larger differences between UAS and manual data of HS could be explained by ice layers in the melting snow. The median difference between the two datasets is, indeed, equal to $0.12 \mathrm{~m}$, whereas the mean difference is equal to $0.20 \mathrm{~m}$. When excluding areas of possible preferential accumulation of water in snow due to topography (hence, ice layers), the observed RMSE decreases to $0.17 \mathrm{~m}$. These results support the use of UAS as a competitive choice among existing alternatives for high-precision highresolution remote sensing of snow.

\section{Data availability}

The presented data are available upon request to the corresponding author.

Author contributions.

Carlo De Michele conceived the study. Alberto Bianchi, Alberto Cina, Carlo De Michele, Paolo Maschio, Livio Pinto, Marco Piras designed the field surveys. Alberto Bianchi, Alberto Cina, Carlo De Michele, Paolo Maschio, Livio Pinto, Lorenzo Rossi, performed the field surveys (realization of the geodetic networks, MulitStation acquisitions and snow height measurements). Daniele Passoni realized the photogrammetric flights. Diana Pagliari performed the photogrammetric processing. Lorenzo Rossi computed the geodetic network 
The Cryosphere Discuss., doi:10.5194/tc-2017-57, 2017

Manuscript under review for journal The Cryosphere

Discussion started: 24 April 2017

(c) Author(s) 2017. CC-BY 3.0 License.

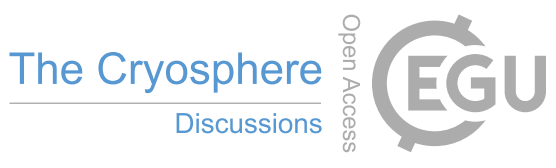

(c) (i)

adjustment. Francesco Avanzi, Carlo De Michele, Diana Pagliari, Livio Pinto and Lorenzo Rossi contributed to data analysis. The manuscript has been prepared with the contribution of all coauthors.

\section{Competing interests.}

Authors declare no conflict of interest.

5 Acknowledgements. The authors would like to thank the students who participated to the Summer School "Design and realization of topographic surveys" (ed. 2015 and 2016) and the Alta Scuola Politecnica (ASP) students (11 ${ }^{\text {th }}$ cycle). We also thank Arpa Piemonte for making available the daily weather data (season 2015 - 2016) and the observed profile of snow properties on March $24^{\text {th }}$ at Rifugio Zamboni, and Dr. Mauro Spanò for fruitful discussions and field logistical support. Educational funds from Alta Scuola Politecnica $\left(11^{\text {th }}\right.$ cycle - project DREAM) are acknowledged. We also acknowledge fruitful discussions with Dr. Ali Nadir Arslan and the Harmosnow Consortium, COST

10 ES 1404 action (www.harmosnow.eu) "A European network for a harmonised monitoring of snow for the benefit of climate change scenarios, hydrology and numerical weather prediction". 
The Cryosphere Discuss., doi:10.5194/tc-2017-57, 2017

Manuscript under review for journal The Cryosphere

Discussion started: 24 April 2017

(c) Author(s) 2017. CC-BY 3.0 License.

\section{References}

Adams, M. S.: Mapping snow depth in alpine terrain with unmanned aerial systems (UASs): potential and limitations, The Cryosphere, 10, $1075,2016$.

Avanzi, F., De Michele, C., Ghezzi, A., Jommi, C., and Pepe, M.: A processing-modeling routine to use SNOTEL hourly data in snowpack dynamic models, Advances in Water Resources, 73, 16-29, doi:10.1016/j.advwatres.2014.06.011, 2014.

Avanzi, F., Hirashima, H., Yamaguchi, S., Katsushima, T., and De Michele, C.: Observations of capillary barriers and preferential flow in layered snow during cold laboratory experiments, The Cryosphere, 10, 2013-2026, doi:10.5194/tc-10-2013-2016, http://www. the-cryosphere.net/10/2013/2016/, 2016.

Bay, H., Ess, A., Tuytelaars, T., and Van Gool, L.: Speeded-up robust features (SURF), Computer vision and image understanding, 110, 346-359, 2008.

Berni, J. A., Zarco-Tejada, P. J., Suárez, L., and Fereres, E.: Thermal and narrowband multispectral remote sensing for vegetation monitoring from an unmanned aerial vehicle, IEEE Transactions on Geoscience and Remote Sensing, 47, 722-738, 2009.

Bühler, Y., Marty, M., Egli, L., Veitinger, J., Jonas, T., Thee, P., and Ginzler, C.: Snow depth mapping in high-alpine catchments using digital photogrammetry, The Cryosphere, 9, 229-243, 2015.

Bühler, Y., Adams, M. S., Bösch, R., and Stoffel, A.: Mapping snow depth in alpine terrain with unmanned aerial systems (UASs): potential and limitations, The Cryosphere, 10, 1075-1088, doi:10.5194/tc-10-1075-2016, http://www.the-cryosphere.net/10/1075/2016/, 2016.

Bühler, Y., Adams, M. S., Stoffel, A., and Boesch, R.: Photogrammetric reconstruction of homogenous snow surfaces in alpine terrain applying near-infrared UAS imagery, International Journal of Remote Sensing, pp. 1-24, 2017.

Cline, D.: Measuring alpine snow depths by digital photogrammetry. Part 1: Conjugate point identification, in: Proceedings of the Eastern Snow Conference, Quebec City, Quebec, pp. 265-271, 1993.

Cline, D. W.: Digital Photogrammetric Determination Of Alpine Snowpack Distribution For Hydrologic Modeling, in: Proceedings of the Western Snow Conference, Colorado State University, CO, USA, 1994.

Colomina, I. and Molina, P.: Unmanned aerial systems for photogrammetry and remote sensing: A review, ISPRS Journal of Photogrammetry and Remote Sensing, 92, 79-97, 2014.

Da Ronco, P. and De Michele, C.: Cloudiness and snow cover in Alpine areas from MODIS products, Hydrology and Earth System Sciences Discussions, 11, 3967-4015, doi:10.5194/hessd-11-3967-2014, http://www.hydrol-earth-syst-sci-discuss.net/11/3967/2014/, 2014.

De Michele, C., Avanzi, F., Ghezzi, A., and Jommi, C.: Investigating the dynamics of bulk snow density in dry and wet conditions using a one-dimensional model, The Cryosphere, 7, 433-444, doi:10.5194/tc-7-433-2013, 2013.

De Michele, C., Avanzi, F., Passoni, D., Barzaghi, R., Pinto, L., Dosso, P., Ghezzi, A., Gianatti, R., and Della Vedova, G.: Using a fixed-wing UAS to map snow depth distribution: an evaluation at peak accumulation, The Cryosphere, 10, 511-522, doi:10.5194/tc-10-511-2016, http://www.the-cryosphere.net/10/511/2016/, 2016.

DeWalle, D. R. and Rango, A.: Principles of Snow Hydrology, Cambridge University Press, 2011.

Dietz, A. J., Kuenzer, C., Gessner, U., and Dech, S.: Remote sensing of snow - a review of available methods, International Journal of Remote Sensing, 33, 4094 - 4134, doi:10.1080/01431161.2011.640964, 2012.

35 Eisenbeiß, H.: UAV photogrammetry, ETH Zurich, Switzerland:, 2009.

El-Gayar, M., Soliman, H., et al.: A comparative study of image low level feature extraction algorithms, Egyptian Informatics Journal, 14, $175-181,2013$. 
The Cryosphere Discuss., doi:10.5194/tc-2017-57, 2017

Manuscript under review for journal The Cryosphere

Discussion started: 24 April 2017

(c) Author(s) 2017. CC-BY 3.0 License.

Farinotti, D., Magnusson, J., Huss, M., and Bauder, A.: Snow accumulation distribution inferred from time-lapse photography and simple modelling, Hydrological Processes, 24, 2087 - 2097, doi:10.1002/hyp.7629, 2010.

Fierz, C., Armstrong, R., Durand, Y., Etchevers, P., Greene, E., McClung, D., Nishimura, K., Satyawali, P., and Sokratov, S.: The International Classification for Seasonal Snow on the Ground, Tech. rep., IHP-VII Technical Documents in Hydrology N 83, IACS Contribution N 1 , UNESCO - IHP, Paris, 2009.

Gini, R., Passoni, D., Pinto, L., Sona, G., et al.: Use of Unmanned Aerial Systems for multispectral survey and tree classification: a test in a park area of northern Italy, European Journal of Remote Sensing, 47, 251-269, 2014.

Grenzdörffer, G., Engel, A., and Teichert, B.: The photogrammetric potential of low-cost UAVs in forestry and agriculture, The International Archives of the Photogrammetry, Remote Sensing and Spatial Information Sciences, 31, 1207-1214, 2008.

Grimm, D. E.: Leica Nova MS50: The World's First MultiStation, GeoInformatics, 16, 22, 2013.

Grünewald, T. and Lehning, M.: Are flat-field snow depth measurements representative? A comparison of selected index sites with areal snow depth measurements at the small catchment scale, Hydrological Processes, 29, 1717-1728, doi:10.1002/hyp.10295, http://dx.doi. org/10.1002/hyp.10295, 2015.

Grünewald, T., Schirmer, M., Mott, R., and Lehning, M.: Spatial and temporal variability of snow depth and ablation rates in a small mountain catchment, The Cryosphere, 4, 215-225, doi:10.5194/tc-4-215-2010, 2010.

Grünewald, T., Stötter, J., Pomeroy, J. W., Dadic, R., Baños, I. M., Marturiá, J., Spross, M., Hopkinson, C., Burlando, P., and Lehning, M.: Statistical modelling of the snow depth distribution in open alpine terrain, Hydrology and Earth System Sciences, 17, 3005-3021, doi:10.5194/hess-17-3005-2013, 2013.

Harder, P., Schirmer, M., Pomeroy, J., and Helgason, W.: Accuracy of snow depth estimation in mountain and prairie environments by an unmanned aerial vehicle, The Cryosphere, 10, 2559-2571, doi:10.5194/tc-10-2559-2016, http://www.the-cryosphere.net/10/2559/2016/, 2016.

Hartley, R. and Zisserman, A.: Multiple view geometry in computer vision, Cambridge university press, 2003.

Helbig, N. and van Herwijnen, A.: Subgrid parameterization for snow depth over mountainous terrain from flat field snow depth, Water Resources Research, doi:10.1002/2016WR019872, 2017.

Hirashima, H., Yamaguchi, S., and Katsushima, T.: A multi-dimensional water transport model to reproduce preferential flow in the snowpack, Cold Regions Science and Technology, 108, 80-90, doi:10.1016/j.coldregions.2014.09.004, 2014.

Hock, R.: Temperature index melt modelling in mountain areas, Journal of Hydrology, 282, 104-115, 2003.

Jaakkola, A., Hyyppä, J., and Puttonen, E.: Measurement of Snow Depth Using a Low-Cost Mobile Laser Scanner, IEEE Geoscience and Remote Sensing Letters, 11, 587-591, 2014.

Johnson, J. B. and Marks, D.: The detection and correction of snow water equivalent pressure sensor errors, Hydrological Processes, 18, 3513-3525, doi:10.1002/hyp.5795, 2004.

Jörg, P., Fromm, R., Sailer, R., and Schaffhauser, A.: Measuring snow depth with a terrestrial laser ranging system, in: Proceedings of the International Snow Science Workshop, 1-6 October 2006, Telluride, Colorado, pp. 452-460, 2006.

Katsushima, T., Yamaguchi, S., Kumakura, T., and Sato, A.: Experimental analysis of preferential flow in dry snowpack, Cold Regions Science and Technology, 85, 206-216, doi:10.1016/j.coldregions.2012.09.012, 2013.

Kattelmann, R.: Spatial variability of snow-pack outflow at a site in Sierra Nevada, U.S.A., Annals of Glaciology, $13,124-128,1989$.

Kattelmann, R. and Dozier, J.: Observations of snowpack ripening in the Sierra Nevada, California, U.S.A., Journal of Glaciology, 45, 409-416, 1999. 
The Cryosphere Discuss., doi:10.5194/tc-2017-57, 2017

Manuscript under review for journal The Cryosphere

Discussion started: 24 April 2017

(c) Author(s) 2017. CC-BY 3.0 License.

Koenderink, J. J. and Van Doorn, A. J.: Affine structure from motion, JOSA A, 8, 377-385, 1991.

Lendzioch, T., Langhammer, J., and Jenicek, M.: Tracking forest and open area effects on snow accumulation by unmanned aerial vehicle photogrammetry, in: The International Archives of the Photogrammetry, Remote Sensing and Spatial Information Sciences, Volume XLIB1, 2016 XXIII ISPRS Congress, 12-19 July 2016, Prague, Czech Republic, 2016.

5 Lingua, A. M., Marenchino, D., and Nex, F. C.: A Comparison between" old and new" feature extraction and matching techniques in photogrammetry, REVISTA DE CADASTRU, 9, 43-52, 2009.

López Moreno, J. I., Fassnacht, S. R., Beguería, S., and Latron, J. B. P.: Variability of snow depth at the plot scale: implications for mean depth estimation and sampling strategies, The Cryosphere, 5, 617-629, 2011.

López Moreno, J. I., Revuelto, J., Fassnacht, S. R., Azorín-Molina, C., Vicente-Serrano, S. M., Morán-Tejeda, E., and Sexstone, G. A.: Snowpack variability across various spatio-temporal resolutions, Hydrological Processes, 29, 1213-1224, 2015.

Lowe, D. G.: Distinctive image features from scale-invariant keypoints, International journal of computer vision, 60, 91-110, 2004.

Machguth, H., Eisen, O., Paul, F., and Hoezle, M.: Strong spatial variability of snow accumulation observed with helicopter-borne GPR on two adjacent Alpine glaciers, Geophyical Research Letters, 33, L13 503, doi:10.1029/2006GL026576, 2006.

Molina, P., Colomina, I., Victoria, T., Skaloud, J., Kornus, W., Prades, R., and Aguilera, C.: Searching lost people with UAVS: The system and results of the CLOSE-SEARCH project, in: International Archives of the Photogrammetry, Remote Sensing and Spatial Information Sciences, vol. 39, pp. 441-446, 2012.

Morin, S., Lejeune, Y., Lesaffre, B., Panel, J.-M., Poncet, D., David, P., and Sudul, M.: An 18-yr long (1993-2011) snow and meteorological dataset from a mid-altitude mountain site (Col de Porte, France, $1325 \mathrm{~m}$ alt.) for driving and evaluating snowpack models, Earth System Science Data, 4, 13-21, doi:10.5194/essd-4-13-2012, http://www.earth-syst-sci-data.net/4/13/2012/, 2012.

20 Newcombe, L.: Green fingered UAVs, Unmanned Vehicle, 2007.

Nex, F. and Remondino, F.: UAV for 3D mapping applications: a review, Applied Geomatics, 6, 1-15, 2014.

Niethammer, U., Rothmund, S., James, M., Travelletti, J., and Joswig, M.: UAV-based remote sensing of landslides, International Archives of Photogrammetry, Remote Sensing and Spatial Information Sciences, 38, 496-501, 2010.

Nolan, M., Larsen, C., and Sturm, M.: Mapping snow depth from manned aircraft on landscape scales at centimeter resolution using structurefrom-motion photogrammetry, The Cryosphere, 9, 1445-1463, doi:10.5194/tc-9-1445-2015, http://www.the-cryosphere.net/9/1445/2015/, 2015.

Pagliari, D., Rossi, L., Passoni, D., Pinto, L., De Michele, C., and Avanzi, F.: Measuring the volume of flushed sediments in a reservoir using multi-temporal images acquired with UAS, Geomatics, Natural Hazards and Risk, pp. 1-17, 2016.

Parajka, J., Haas, P., Kirnbauer, R., Jansa, J., and Blöschl, G.: Potential of time-lapse photography of snow for hydrological purposes at the small catchment scale, Hydrological Processes, 26, 3327-3337, 2012.

Prokop, A., Schirmer, M., Rub, M., Lehning, M., and Stocker, M.: A comparison of measurement methods: terrestrial laser scanning, tachymetry and snow probing for the determination of the spatial snow-depth distribution on slopes, Annals of glaciology, 49, 210-216, 2008.

Revuelto, J., Vionnet, V., López-Moreno, J.-I., Lafaysse, M., and Morin, S.: Combining snowpack modeling and terrestrial laser scanner observations improves the simulation of small scale snow dynamics, Journal of Hydrology, 533, 291 - 307, doi:http://dx.doi.org/10.1016/j.jhydrol.2015.12.015, //www.sciencedirect.com/science/article/pii/S0022169415009634, 2016.

Schweizer, J., Kronholm, K., Bruce Jamieson, J., and Birkeland, K. W.: Review of spatial variability of snowpack properties and its importance for avalanche formation, Cold Regions Science and Technology, 51, 253-272, doi:10.1016/j.coldregions.2007.04.009, 2008. 
The Cryosphere Discuss., doi:10.5194/tc-2017-57, 2017

Manuscript under review for journal The Cryosphere

Discussion started: 24 April 2017

(C) Author(s) 2017. CC-BY 3.0 License.

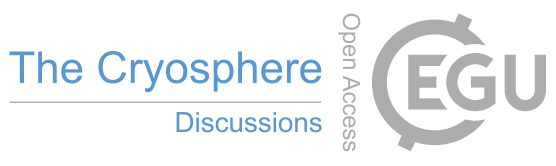

(c) (i)

Scipión, D., Mott, R., Lehning, M., Schneebeli, M., and Berne, A.: Seasonal small-scale spatial variability in alpine snowfall and snow accumulation, Water Resources Research, 49, 1446-1457, doi:10.1002/wrcr.20135, 2013.

Smith, F., Cooper, C., and Chapman, E.: Measuring Snow Depths by Aerial Photography, in: Proc Western Snow Conf,, pp. 66-72, 1967.

Sturm, M.: White water: Fifty years of snow research in WRR and the outlook for the future, Water Resources Research, 51, 4948-4965, 52015.

Tao, T. S. and Hansman, R. J.: Development of an In-Flight-Deployable Micro-UAV, in: 54th AIAA Aerospace Sciences Meeting, p. 1742, 2016.

Tauro, F., Porfiri, M., and Grimaldi, S.: Surface flow measurements from drones, Journal of Hydrology, 540, 240-245, 2016.

Thamm, H. and Judex, M.: The "low cost drone" - an interesting tool for process monitoring in a high spatial and temporal resolution, in: ISPRS Mid-term Symposium, pp. 8-11, 2006.

Vander Jagt, B., Lucieer, A., Wallace, L., Turner, D., and Durand, M.: Snow depth retrieval with UAS using photogrammetric techniques, Geosciences, 5, 264-285, 2015. 